\title{
Gestational Hypertension: Overview and Current Recommendations
}

\author{
Sujata Raosaheb Palve \\ Department of Obstetrics and Gynaecological Nursing, College of Nursing, Government Medical College, Aurangabad, Maharashtra, India
}

\section{Abstract}

Hypertension is one of the common complications met with in pregnancy and contributes significantly to maternal and perinatal morbidity and mortality. Hypertension is a sign of underlying pathology which may be preexisting or appears for the $1^{\text {st }}$ time during pregnancy. The identification of clinical entity and effective management plays a significant role in the outcome of pregnancy, both for the mother and the baby. In the developing countries with uncared pregnancy, this entity on many occasions remains undetected till major complications supervene. Hypertensive disorders of pregnancy represent a group of conditions associated with high blood pressure during pregnancy, proteinuria, and in some cases convulsions. The most serious consequences for the mother and the baby result from preeclampsia and eclampsia. In India, the incidence of preeclampsia is reported to be $8-10 \%$ of the pregnancies. Hypertension in pregnancy strikes mostly the primigravidae women after the $20^{\text {th }}$ week of gestation and frequent occurrences are seen near term. It contributes significantly to the cause of maternal and perinatal mortality and morbidity. The goal of the treatment of gestational hypertension is to prevent significant cerebrovascular and cardiovascular events in the mother, without compromising fetal well-being. A woman's health lies in her hand. She alone is responsible for her health. Hence, the mother needs to be aware of regular antenatal checkup, follow-up the medical regimen, and adapt self-care management to prevent pregnancy-induced hypertension (PIH) and thereby safe childbirth. This review will address background, risk factors, pharmacological, non-pharmacological management of hypertension in pregnancy, and the role of planned teaching in PIH.

Keywords: Gestational Hypertension, pregnancy, medical regimen

\section{BACKGROUND}

Hypertension is the persistent elevation of blood pressure. There is no natural dividing line between normal blood pressure and hypertension. The simplified definition by the World Health Organization Experts Committee (1978) is, "hypertension in adults of a systolic pressure equal to or $>160 \mathrm{mmHg}$ and/or diastolic blood pressure $>90 \mathrm{mmHg}$. ${ }^{[1]}$ Blood pressure is the force of that the blood applies to the wall of the arteries when it flows through them. It is normal for blood pressure to increase when you exert yourself or when you feel stressed or anxious. However, if the blood pressure is consistently higher than normal at rest, it is known as hypertension.

\begin{tabular}{|l|}
\hline \multicolumn{1}{|c|}{ Access this article online } \\
\hline Website: http://innovationalpublishers.com/Journal/ijnmi \\
\hline ISSN No: $2656-4656$ \\
DOI: $10.31690 /$ ijnmi/42 \\
\hline
\end{tabular}

Hypertension in pregnancy is a universally common disease. The normal growth and development of the fetus can be adversely affected by a number of factors such as infection and complications during pregnancy such as pregnancy-induced hypertension (PIH) and diabetes. In PIH, a woman begins her pregnancy with a normal blood pressure, but it rises sometimes during the third trimester. The criterion to be met, before suspecting $\mathrm{PIH}$ is a rise in the systolic number of $30 \mathrm{and} /$ or a rise of the diastolic number of 15 . Preeclampsia is a condition that starts after the $20^{\text {th }}$ week of pregnancy and is related to high blood pressure and protein in the mother's urine along with swelling on the face and legs. High blood pressure can be dangerous for both the mother and the fetus. The effects of increased blood pressure range from mild to severe. ${ }^{[2]}$

Preeclampsia and eclampsia cause blood vessels to leak. Fluid flows into body tissue and results in the swelling of the extremities and face. This causes pregnant women to experience significant weight gain. The eyes can become affected and the vision becomes blurry. The retina can become 
detached. Fluid can leak into the lungs, causing shortness of breath. Leaky vessels in the liver can cause it to swell and cause a serious condition called the hemolysis, elevated liver enzyme levels, and a low platelet count (HELLP) syndrome. ${ }^{[3]}$

Protein leaked into the kidneys results in low birth weight babies with higher risks of complications, including death. Leaky vessels within the brain can cause seizures and coma. The most serious consequence of preeclampsia and eclampsia is brain damage to the mother caused by brain swelling and oxygen loss during seizures.

The mother can also experience blindness, liver rupture, kidney failure, and placental abruption (a life-threatening condition to both mother and baby that occurs when there is a disruption of blood flow to the placenta). PIH can result in vasospasm of the blood vessels of both the mother and the placenta. This means the blood vessels, which are delivering oxygen and other needed nutrients to the mother and baby, alternately clamp down and relax, causing damage to the interior lining of the blood vessels. ${ }^{[4]}$

As the body tries to repair the damaged vessels, clots may form at the site, resulting in more constriction and narrowing of the blood vessels. Continued vasospasm, along with the formation of these miniature blood clots, can reduce blood flow and oxygen supply to both the mother's vital organs and the placenta.

Depending on the severity of this condition, the heart, kidney, liver, and brain in the mother may be affected. If the blood supply to the placenta is interrupted, the baby cannot grow well. The disturbance in blood flow to the placenta also can result in a condition called placental abruption. Placenta abruption is a medical emergency that places both the lives of the mother and fetus at risk. ${ }^{[2]}$

The most important thing that a pregnant woman can do to detect this disorder is to receive regular prenatal examinations. Serious problems are usually prevented in women who develop this disorder if they are receiving regular prenatal care.

\section{RISK FACTORS AND COMPLICATIONS}

Zhao and Wang evaluated an assessment of the risk factors of PIH, development of measures to prevent PIH, and related obstetrical complications. Of the total sample size of 3205 pregnant women, 219 cases were found to have PIH. Related data were gathered with the help of a questionnaire and measurements. Results showed that there was an increased incidence of PIH among women with advanced age and having family history of hypertension. Furthermore, incidence of PIH increased among obese/heavier weight women. Therefore, it was concluded that it is necessary to strengthen screening programs of PIH for women with advanced age, family history of hypertension, and obesity. ${ }^{[5]}$

Thadani et al. studied relation between pregravida oral contraceptive use and risk of hypertensive disorders of pregnancy. The sample consisted of 3973 nulliparous women who reported their first pregnancy lasting for more than 6 months. Data were collected by biennial marked questionnaires and cases of PIH were confirmed by a medical record review. During the 4 years (1991-1995), of followup, $133(3.3 \%)$ women with gestational hypertension and $62(1.6 \%)$ with preeclampsia were identified. The study was concluded with the findings that the recent use of oral contraceptive pills was associated with an increased risk of developing preeclampsia, but only among women who had used these agents for more than 8 years. ${ }^{[6]}$

Yin et al. evaluated the relationship of pre-pregnant weight and weight gain during pregnancy with $\mathrm{PIH}$ and birth weight at Guangzhou, China. Sample consisted of 769 primigravida mothers giving full-term birth to a single baby. Pre-pregnant body mass index and pregnancy weight gain of respective samples were measured as well as the pregnancy outcomes were followed up. Results of the study showed that the incidence of pregnancy reduced hypertension and fetal macrosomia was significantly higher in the overweight samples (weight gain $18 \mathrm{~kg}$ during pregnancy) than in the normal weight and underweight. Therefore, it hided that prepregnant body mass index and weight gain during pregnancy can be important: It is influencing the occurrence of PIH and the neonate's birth weight. ${ }^{[7]}$

Buhling studied risk factors for gestational diabetes and hypertensive for women with twin pregnancy against singleton pregnancy. Sample consisted of 89 patients with twin pregnancy who sought perinatal care between September 1, 1994, and October 30, 1997. The diagnosis "hypertensive preeclampsia" was made by following clinical criteria of a repeated blood pressure above $140 / 90 \mathrm{mmHg}$. Analyzed data showed that patient with twin pregnancies did not have a high rate of gestational diabetes but of PIH. Furthermore, it was seen that expecta mothers of twins with abnormal glucose screening test have a higher incidence of hypertension than those whose screening test was normal. Therefore, it was concluded that patients expect twins and also having carbohydrate intolerance are at a higher risk for hypertension and diabetes-associated complications. ${ }^{[8]}$

Bjelica et al. suggested that pregnancy as a stress-inducing situation may lead to transformation of emotional tension to biochemical and vegetative response and thus contribute to onset of PIH. ${ }^{[9]}$ Malamitsi-Puchner and Boutsikou stated that one of the important maternal complications related to adolescent pregnancy is PIH along with others such as anemia and sex transmitted diseases. ${ }^{[10]}$ Tournadre reported that sleep apnea syndrome symptoms are frequent during pregnancy and snoring appears to be linked with PIH. ${ }^{[1]}$

Forest et al. observed that the prevalence of metabolic syndrome is three to the times increased in women with a history of PIH. Thus, the result emphasizes on the importance of long-term follow-up assessment for cardiovascular risk factors in PIH women. ${ }^{[12]} \mathrm{Kim}$ et al. suggested that women 
with PIH more often reported a significant decline in vitality self-related health and increase in depressive symptoms from pregnancy to postpartum when compared to unaffected woman. Further, it was concluded that women with PIH but not gestational diabetes mellitus, more often experience significant decline in health status from prepregnancy to postpartum than the unaffected women. ${ }^{[13]}$

Allen et al. reported that women with any hypertension in pregnancy were 1.6 times more likely to have a live birth with small for gestational age and 1.4 times more likely to have stillbirth as compared with normotensive women. ${ }^{[14]}$ Baulon et al. showed that infants born to mothers with PIH but without intrauterine growth retardation have normal early infant growth, but infants weighed at 28 and 42 days postpartum were significantly lower, in severe preeclampsia and preeclampsia group than in the normotensive groups. ${ }^{[15]}$ Wells suggested that there was no significantly positive relationship between sensory neural hearing loss and PIH. ${ }^{[16]}$

Singh et al. reported that eclampsia can be prevented or reduced by social and economic upliftment along with efficient transport facilities and decentralization of obstetric services. ${ }^{[17]}$ Doshi et al. suggested that we can prevent eclampsia, but we cannot prevent preeclampsia. ${ }^{[18]}$ Meenabai suggested that family members involvement, dietary modification, and antiplatelet test can effectively predict the development of preeclampsia. Although primary, secondary, and tertiary prevention play a role, prompt most can effectively prevent life-threatening complications. ${ }^{[19]}$

\section{Pharmacological treatment of PIH}

Tewari et al. indicated that low-dose aspirin plays an important role in prevention of PIH. ${ }^{[20]}$ Cong et al. supported the use of calcium supplementation during pregnancy to reduce the risk of PIH. ${ }^{[21]}$

Ritchie suggested that high-risk groups, such as pregnant teens, populations with inadequate calcium intake, and women at risk of developing $\mathrm{PIH}$, may benefit from consuming additional dietary calcium. ${ }^{[22]} \mathrm{Li}$ and Tian reported that low-dose magnesium gluconate may effectively prevent $\mathrm{PIH}$ in highrisk women. ${ }^{[23]}$

\section{Non-pharmacological and dietary management}

Canino et al. suggested the use of deep muscle relaxation in the prevention of PIH. Canino et al. suggested that yoga relaxation is seen as beneficial in reduction of blood pressure. ${ }^{[24]}$ Narendran et al. found that an integrated approach to yoga during pregnancy is safe; it improves birth weight, decreases preterm labor, and decreases intrauterine growth retardation or associated with PIH with no increased complications. ${ }^{[25]}$

Nagarathna et al. showed that occurrence of complications of pregnancy $(\mathrm{PIH}$, intrauterine growth retardation, and preterm delivery) shows lower trends in the yoga group. ${ }^{[26]}$ An article from "daily news and analysis" a newspaper dated June 30, 2006, stated that physical activity reduces blood pressure even if patients take medications for the problem. A study says walking 3 times a week lowers blood pressure. ${ }^{[27]}$

Dietary approaches to stop hypertension trial suggested that dietary changes are essential for achieving and maintaining normal blood pressure and those nutrients from diet work in a complex manner. ${ }^{[28]} \mathrm{An}$ article published in "daily news and analysis" newspaper from Mumbai Dated July 15, 2005 - IQL mentioned that low-fat food such as milk, cheese, and yogurt lower blood pressure, also people must follow a diet rich in fruits, vegetables, whole grains, and potassium calcium which are in daily foods. ${ }^{[29]}$

Mr. V. Mohan President of Madras Diabetes Research Foundation published an article in "Maharashtra times" a Marathi newspaper dated September 7, 2006, emphasized that it is very beneficial to have at least one banana in a day as it contains less sodium and high potassium, it is helpful in controlling the blood pressure and reduces the chances of heart diseases. ${ }^{[30]}$

\section{Role of planned teaching}

"Health education is one of the most cost-effective interventions. A large number of diseases could be prevented with little or no medical intervention if the mothers were adequately informed about them and if they were adequately encouraged to take the necessary precaution in time. The educational approach is a major means today for achieving changes in the health practices and for the recognition of health needs." The World Health Organization Report (1995).

Planned teaching really helps the individual to understand the consequences of their actions either good or harmful. It also indicates how they can adopt certain behavior which helps in healthy living. Planned teaching also involves innovation, motivation, communication, and decision-making, the results though slow, are enduring and sufficient time, should be allowed to have the desired change to be brought about. There are certain problems that can be solved only through education, for example, child care, antenatal mother care, breastfeeding, family planning, etc. ${ }^{[31]}$ There is a good deal of evidence that group education is an effective method of bringing about changes in the health care of people. The collective acceptance strengthens, reinforces, and gives the individual the motivation to put it in practice.

There is a good deal of evidence that group education is an effective method of bringing about changes in the health care of people and it is reflected in the following studies.

Gopal (1998) aimed to find out the importance of planned teaching program on the knowledge and skill of the staff nurses regarding basic life support of cardiopulmonary resuscitation (CPR) sample consisted of 50 staff nurses. The findings of the study revealed that nurses gained significantly higher knowledge regarding CPR $(P<0.01)$ after exposure to the planned teaching program. The nurses demonstrated significantly better skill to perform basic life support functions $(P<0.01)$ after demonstration. ${ }^{[32]}$ 
Effect of planned teaching on knowledge and performance of nurses in maintaining oral hygiene of patients with endotracheal tube was studied by Marino A on 50 staff nurses working in different Intensive Care Units of K.E.M Hospital, Mumbai, participated as samples. A pre-test and post-test method was used to assess the knowledge of the sample. The calculated value of " $\mathrm{t}$ " was found to be statistically significant at $P<0.01$ level. This indicated that the planned teaching has a positive effect on the knowledge of nurses. The performance was assessed after planned teaching and it showed positive correlation and marked relationship between knowledge and practices of the sample. ${ }^{[33]}$

In one more published study with an aim "to assess the effect of planned teaching on knowledge and performance of nurses carrying out endotracheal suctioning for mechanically ventilated patients" was conducted by Sawant C. A sample consisted of 50 staff nurses. A pre-test and post-test were used to assess the knowledge of the samples. The calculated value of the " $\mathrm{t}$ " was found to be statistically significant at 0.01 level of significance. This indicated that planned teaching has a positive effect on the knowledge of nurses. ${ }^{[34]}$

The investigator from her own experience identified the topic of the study and based on the above review; the investigator felt convinced that the need of the hour is patient's education, which is the best and only answer. The literature review helped the investigator to clear her concept, develop in-depth understanding of the issue and in formulating the questionnaire. It also helped the investigator to have a wider understanding of the topic of the study. The investigator gained knowledge while contributed to the preparation of the tool, methodology, and the plan for data collection and analysis.

\section{Conclusion}

There is a need to increase awareness among medical and paramedical personnel on the need for increasing awareness of the knowledge of women with the previous history of preeclampsia, multiple gestation, gestational diabetes, and obesity for specialist care as they have a higher risk of developing hypertensive disorders. Knowledge of the women can be increased using planned teaching to effectively reduce incidences of PIH.

\section{RefEREnCES}

1. Catherine TJ. A study on the effect of relaxation, exercise on blood pressure in hypertensive subjects attending outpatient depart in K.E.M Hospital, Mumbai. Dis Cat 616-132.

2. Dutta DC. Text Book of Obstetrics. $6^{\text {th }}$ ed. Culcutta: New Central Book Agency Private Ltd.; 2002. p. 221-40.

3. Kathe GB. Health Guide, Pre-Eclampsia and High Blood Pressure during Pregnancy. Available from: http://www.sh-print.Healthwise. net/webprint mgraspx?c=moh\&s=en-caQ10. [Last accessed on 2006 Apr 14].

4. Margaret M. A Text Book for Midwifery. $8^{\text {th }}$ ed. Edinburgh: Churchill Living Stone; 1989. p. 310-5.

5. Zhao W, Wang JH. Screening program and risk factors on pregnancyinduced hypertension syndrome. Zhonghua Liu Xing Bing Xue Za Zhi
2004;25:845-7.

6. Thadhani R, Stampfer MJ, Chasan-Taber L, Willett WC, Curhan GC. A prospective study of pregravid oral contraceptive use and risk of hypertensive disorders of pregnancy. Contraception 1999;60:145-50.

7. Yin YZ, Chen XW, Li XM, Hou HY, Zhou SS. Relations of prepregnant weight and weight gain during pregnancy with pregnancyinduced hypertension and birth weight. Di Yi Jun Yi Da Xue Xue Bao 2005;25:226-8.

8. Buhling KJ, Henrich W, Starr E, Lubke M, Bertram S, Siebert G, et al. Risk for gestational diabetes and hypertension for women with twin pregnancy compared to singleton pregnancy. Arch Gynecol Obstet 2003;269:33-6.

9. Bjelica A. Pregnancy as a stressful life event and strategies for coping with stress in women with pregnancy-induced hypertension. Med Pregl 2004;57:363-8.

10. Malamitsi-Puchner A, Boutsikou T. Adolescent pregnancy and perinatal outcome. Pediatr Endocrinol Rev 2006;3 Suppl 1:170-1.

11. Calaora-Tournadre D, Ragot S, Meurice JC, Pourrat O, D'Halluin G, Magnin G, et al. Obstructive sleep apnea syndrom during pregnancy: Prevalence of main symptoms and relationship with pregnancy inducedhypertension and intra-uterine growth retardation. Rev Med Interne 2006;27:291-5.

12. Forest JC, Girouard J, Massé J, Moutquin JM, Kharfi A, Ness RB, et al. Early occurrence of metabolic syndrome after hypertension in pregnancy. Obstet Gynecol 2005;105:1373-80.

13. Kim C, Brawarsky P, Jackson RA, Fuentes-Afflick E, Haas JS. Changes in health status experienced by women with gestational diabetes and pregnancy-induced hypertensive disorders. J Womens Health (Larchmt) 2005;14:729-36.

14. Allen VM, Joseph K, Murphy KE, Magee LA, Ohlsson A. The effect of hypertensive disorders in pregnancy on small for gestational age and stillbirth: A population based study. BMC Pregnancy Childbirth 2004;4:17.

15. Baulon E, Fraser WD, Piedboeuf B, Buekens P, Xiong X. Pregnancyinduced hypertension and infant growth at 28 and 42 days postpartum. BMC Pregnancy Childbirth 2005;5:10.

16. Wells MD. Pregnancy-induced hypertension and congenital hearing loss. Int J Pediatr Otorhinolaryngol 1991;22:39-47.

17. Singh U, et al. Eclampsia on Obstetric Enigma. Federation of Obstetrics and Gynecological Society of India. $48^{\text {th }}$ All India Congress of Obstetrics and Gynecology; Abstract. Aurangabad: FOGSL; 2005. p. 519.

18. Doshi S, et al. Three Years Study of Pre-Eclampsia in Rural Private Hospital. Federation of Obstetrics and Gynecological Society of India. $48^{\text {th }}$ All India Congress of Obstetrics and Gynecology; Abstract. Aurangabad: FOGSI; 2005. p. 251.

19. Meenambai P. Delivery is Still the Ultimate Cure for Pre-Eclampsia, Prevention of PIH: How far Possible? PP31 in Federation of Obstetrics and Gynecological Society of India. $48^{\text {th }}$ All India Congress of Obstetrics and Gynecology; Abstract. Aurangabad: FOGSI; 2005.

20. Tewari S, Kaushish R, Sharma S, Gulati N. Role of low dose aspirin in prevention of pregnancy induced hypertension. J Indian Med Assoc 1997;95:43-4, 47.

21. Cong K, Chi S, Liu G. Calcium supplementation during pregnancy for reducing pregnancy induced hypertension. Chin Med J (Engl) 1995;108:57-9.

22. Ritchie LD, King JC. Dietary calcium and pregnancy-induced hypertension: Is there a relation? Am J Clin Nutr 2000;71:1371S-4S.

23. Li S, Tian H. Oral low-dose magnesium gluconate preventing pregnancy induced hypertension. Zhonghua Fu Chan Ke Za Zhi 1997;32:613-5.

24. Canino E, Cardona R, Monsalve P, Acuña FP, López B, Fragachan F, et al. A behavioral treatment program as a therapy in the control of primary hypertension. Acta Cient Venez 1994;45:23-30.

25. Narendran S, Nagarathna R, Narendran V, Gunasheela S, Nagendra HR. Efficacy of yoga on pregnancy outcome. J Altern Complement Med 2005;11:237-44.

26. Narendran S, Nagarathna R, Gunasheela S, Nagendra HR. Efficacy of yoga in pregnant women with abnormal Doppler study of umbilical and uterine arteries. J Indian Med Assoc 2005;103:12-4, 16-7.

27. Daily News and Analysis. Physical Activity Reduces Blood Pressure. Mumbai: Daily News; 2006. 
28. Allina Hospitals and Clinics Garlic. Available from: http://www. abbottnorthwestern.com/ac/CAM.nsf/consherbs/Garlicch.html. [Last accessed on 2006 May 27].

29. Daily News and Analysis. A Daily Dose of Dairy Products May Help with Hypertension. Mumbai: Daily News; 2006.

30. Mohan V. A Banana Day. Mumbai Times, a Supplement of Marathi Newspaper Maharashtra Times. Mumbai: Mumbai Times; 2006.

31. Fundazioa E. Skimmed milk reduces the risk o f hypertension by 50\%. Am J Clin Nutr 2005;365:217-23. Available from: http://www. sciencedany.eom/releases/2005/1 1/051130232022.htm. [Last accessed on 2005 Dec 01].

32. Gopal HR. Astudy to find out the Impact of Planned Teaching Program on Knowledge and Skills of Staff Nurses Regarding Basic Life Support Measures of CPR. Unpublished Master of Nursing Dissertation.
Mumbai: SNDT Women's University; 1998.

33. Marino A. A Study to find out the Effect of Planned Teaching on Knowledge and Performance of Nurses in Maintaining Oral Hygiene of Patients with Endotracheal Intubation. Unpublished Master of Nursing Dissertation. Mumbai: SNDT Women's University; 1990.

34. Sawant C. A Study to find out the Effect of Planned Teaching on Knowledge and Performance of Nurses in Carrying out Endotracheal Suctioning for Mechanically Ventilated Patients. Unpublished Master of Nursing Dissertation. Mumbai: SNDT Women’s University; 2005.

How to cite this article: Palve SR. Gestational Hypertension: Overview and Current Recommendations.. Int J Nurs Med Invest. 2019;4(2):7-11 